\title{
Isolation and Transcriptomic Profiling of Single Myofibers from Mice
}

Francesco Chemello1, *,\#, Enrico Alessio1, \#, Lisa Buson¹, Beniamina Pacchioni1 ${ }^{1,2}$, Caterina Millino ${ }^{1,2}$, Gerolamo Lanfranchi ${ }^{1,2,3, *}$ and Stefano Cagnin ${ }^{1,2,3, *}$

${ }^{1}$ Department of Biology, University of Padova, Padova, Italy; ${ }^{2} \mathrm{CRIBI}$ Biotechnology Center, University of Padova, Padova, Italy; ${ }^{3} \mathrm{CIR}$-Myo Myology Center, University of Padova, Padova, Italy

*For correspondence: $\quad$ francesco.chemello@gmail.com; gerolamo.lanfranchi@unipd.it; stefano.cagnin@unipd.it

\#Contributed equally to this work

[Abstract] Skeletal muscle is composed of different cells and myofiber types, with distinct metabolic and structural features. Generally, transcriptomic analysis of skeletal muscle is performed using whole muscle, resulting in average information as all cells composing the organ contribute to the expression value detected for each gene with the loss of information about the distinctive features of each specific myofiber type. Since myofibers are the smallest complete contractile system of skeletal muscle influencing its contraction velocity and metabolism, it would be beneficial to have fiber-specific information about gene expression. Here, we describe a protocol for the isolation and the transcriptomic analysis of single individual myofibers. The protocol was set up using single myofibers isolated from soleus and Extensor Digitorum Longus (EDL) muscles, but it can be applied to all skeletal muscles. Briefly, muscles are enzymatically dissociated and individually collected. Long RNAs (> $200 \mathrm{nt})$ and short RNAs ( $<200 \mathrm{nt})$ are separately purified from each myofiber and used to produce libraries for microarray or sequencing analysis. Through this approach, myofiber-specific transcriptional profiles can be produced, free from transcripts from other non-contractile cell types, in order to identify mRNA-miRNA-IncRNA regulatory networks specific for each myofiber type.

Keywords: Single myofiber, Transcriptomic analysis, Skeletal muscle, Non-coding RNAs, miRNAs, Regulatory network

[Background] Skeletal muscle is a complex organ and heterogenous tissue. It is composed by different cell types such as those from blood, vessels, nerves, connective tissue, and myofibers, that are the smallest complete contractile system of skeletal muscle influencing both its mechanical performance and metabolism. In addition, myofibers are classified into different types. In mouse, type I myofibers display slow-twitch contraction and oxidative metabolism, type IIA and IIX myofibers fast-twitch contraction and oxidative metabolism, and type IIB myofibers fast-twitch contraction and glycolytic metabolism (Schiaffino and Reggiani, 2011). The preferential metabolism of each muscle is defined by the different proportion of myofiber types. Soleus muscle is mainly composed by type I, type IIA, and type 2X oxidative myofibers, and preferentially consumes lipids, whereas EDL muscle by type IIB glycolytic myofibers, and primarily uses carbohydrates as energy substrate (Augusto et al., 2004). To investigate differences in muscle metabolism and contraction at transcriptomic level, previous expression profiles were obtained using 
soleus and EDL whole muscles (Campbell et al., 2001; Wu et al., 2003). Results described in these works are influenced by the different contributions of diverse cells composing whole muscle (Figure $1 \mathrm{~A}$ ) and lose the transcriptional specificity of myofiber types (Figure 1B). We demonstrated the feasibility of scaling down the transcriptomic analysis of skeletal muscle at single isolated myofiber level for mRNA, long noncoding RNA (IncRNA) and microRNA (miRNA) populations (Figure 1C). This approach allowed the identification of expression profiles, free from non-myofiber cells (Chemello et al., 2011), and allowed the generation of mRNA-miRNA-IncRNA regulatory networks specific for each myofiber type (Alessio et al., 2019; Chemello et al., 2019). Moreover, it is easier to characterize perturbations that exclusively affect myofibers (Chemello et al., 2015; Mammucari et al., 2015), and to improve the description and comprehension of muscle atrophy (Alessio et al., 2019). In fact, muscle atrophy induces significant systemic metabolic modifications (Celegato et al., 2006) also in a myofiber-specific manner (Wang and Pessin, 2013).

A

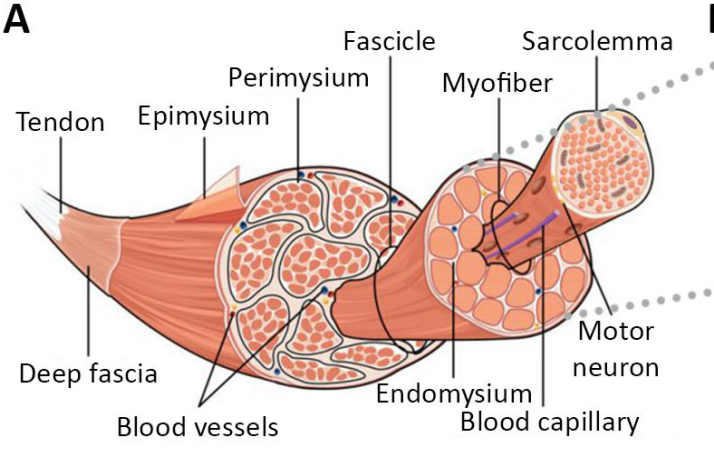

B

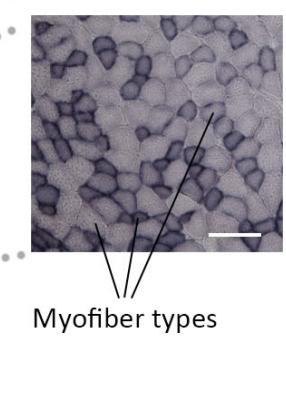

C

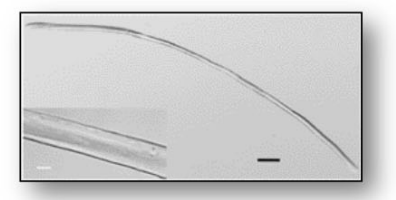

EDL single fiber

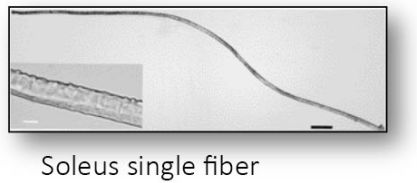

Figure 1. Complexity of skeletal muscle. A. Structure of the skeletal muscle with the different tissues and cells that make up its structure. Image modified from (Biga et al., 2019). B. Succinate Dehydrogenase Staining (SDH) shows different myofiber types in a transversal muscle cross-section. Scale bar is for $100 \mu \mathrm{m}$. C. Images of single isolated myofibers from EDL and soleus muscles. Scale bar is for $250 \mu \mathrm{m}$. From each single myofibers is possible to profile the expression of long and short RNAs.

\section{Materials and Reagents}

1. $200 \mu$ tips

2. DNA LoBind tubes (Eppendorf, catalog number: 0030108051 or Serstedt, catalog number: 72.706.700)

3. Spin-X centrifuge tubes (Corning-Costar, catalog number: CLS8160-96EA)

4. RNase/DNase free Eppendorf microcentrifuge tube

5. $0.2 \mathrm{ml} \mathrm{PCR}$ tube

6. Hybridization gasket slides, 8 microarrays/slide (Agilent, catalog number: G2534-60014)

7. Cell culture plates: 24-well and 6-well plates

8. Plastic Pasteur pipettes 
9. Slide-staining dishes

10. Adult wild-type mice, weight: $33-35 \mathrm{~g}$

Note: We used CD1 mouse strain.

11. High-glucose Dulbecco's modified Eagle medium (DMEM) (Millipore Sigma, catalog number: D5796)

12. 2,3-Butanedione monoxime (BDM) (Sigma-Aldrich, catalog number: B0753)

13. Agencourt AMPure XP beads (Beckman Coulter, catalog number: A63881)

14. Collagenase from Clostridium histolyticum, type I (Millipore Sigma, catalog number: C0130)

15. Fetal bovine serum (FBS) (Millipore Sigma, catalog number: F2442)

16. Phosphate-buffered saline (PBS) (Thermo Fisher Scientific, catalog number: 20012019)

17. TRIzol Reagent (Thermo Fisher Scientific, catalog number: 15596026)

18. Nuclease-free water (Thermo Fisher Scientific, catalog number: 10977035)

19. Nuclease-free water (Ambion, catalog number: AM9937)

20. Chloroform (PanReac AppliChem, catalog number: 121252)

21. $70 \% \mathrm{v} / \mathrm{v}$ ethanol (dilute ethanol in nuclease-free water)

22. $75 \% \mathrm{v} / \mathrm{v}$ ethanol (dilute ethanol in nuclease-free water)

23. $80 \% \mathrm{v} / \mathrm{v}$ ethanol (dilute ethanol in nuclease-free water)

24. Absolute ethanol

25. miRNeasy kit (Qiagen, catalog number: 217004)

26. RNeasy micro kit (Qiagen, catalog number: 74004)

27. Complete Whole Transcriptome Amplification Kit (Millipore Sigma, catalog number: WTA2)

28. GenElute PCR Clean-Up Kit (Millipore Sigma, catalog number: NA1020)

29. SureTag DNA Labeling Kit (Agilent, catalog number: 5190-3400)

30. Gene Expression Hybridization Kit (Agilent, catalog number: 5190-0404)

31. Gene Expression Wash Buffer Kit (Agilent, catalog number: 5188-5327)

32. SurePrint G3 Mouse GE 8x60K Microarray Kit (Agilent, catalog number: G4852A)

33. Poly(A) Tailing Kit (Thermo Fisher Scientific, catalog number: AM1350)

34. Sodium Acetate 3 M (pH 5.5) (Thermo Fisher Scientific, catalog number: AM9740)

35. SuperScript II Reverse Transcriptase (Thermo Fisher Scientific, catalog number: 18064014)

36. Oligo-dT-Ion P1 adapter primer (5'-CCTCTCTATGGGCAGTCGGTGATCCTCAGC[dT] ${ }_{20} \mathrm{VN}-3^{\prime}$ )

37. SMART primer (5'-CACACACAATTAACCCTCACTAAAggg-3')

38. Ion Xpress Plus gDNA Library (Thermo Fisher Scientific, catalog number: 4471269)

39. PGM HI-Q OT2 kit (Thermo Fisher Scientific, catalog number: A27739)

40. Platinum Taq DNA Polymerase High Fidelity (Thermo Fisher Scientific, catalog number: 11304011)

41. E-Gel SizeSelect Gels (Thermo Fisher Scientific, catalog number: G661012)

42. DNA ladder 50 bp (Thermo Fisher Scientific, catalog number: 10416014)

43. High Sensitivity DNA kit (Agilent, catalog number: 5067-4626)

44. Ion OneTouch Template Kit (Thermo Fisher Scientific, catalog number: A29900)

45. 1x Low TE buffer (see Recipes) 


\section{Equipment}

1. Micropipette (P10, P20)

2. $-80^{\circ} \mathrm{C}$ freezer

3. $-20^{\circ} \mathrm{C}$ freezer

4. Forceps and scissors for microdissection

5. $37^{\circ} \mathrm{C}$ incubator

6. Stereo-microscope

7. Refrigerated microcentrifuge

8. SpeedVac concentrator

9. Thermocycler

10. Nanodrop spectrophotometer

11. Heat block

12. Centrifuge

13. Agilent SureHyb chamber (Agilent, catalog number: G2534A)

14. Hybridization oven (Agilent, model: G2545A)

15. Hybridization oven rotator (Agilent, model: G2530-60029)

16. Agilent scanner system (Agilent, model: G2505C)

17. DynaMag (Thermo Fisher Scientific, catalog number: 12321D)

18. Ion Torrent, or Ion S5 System (Thermo Fisher Scientific)

19. E-Gel ${ }^{\mathrm{TM}}$ Electrophoresis Device (Thermo Fisher Scientific)

20. Agilent 2100 Bioanalyzer (Agilent)

21. Ion OneTouch Instrument (Thermo Fisher Scientific)

22. Ion PGM sequencing instrument (Thermo Fisher Scientific)

\section{Software}

1. Bioanalyzer software (Agilent, https://www.agilent.com/en/product/automatedelectrophoresis/bioanalyzer-systems/bioanalyzer-instrument/2100-bioanalyzer-laptop-228251 Company or Developer/Provider/Supplier, web address)

2. Feature Extraction Software (Agilent, https://www.agilent.com/en/product/mirna-microarrayplatform/mirna-microarray-software/feature-extraction-software-228496)

3. R statistical software (https://www.r-project.org/)

4. MultiExperiment Viewer (https://sourceforge.net/projects/mev-tm4/)

5. miRDeep software (https://sourceforge.net/projects/mirdeepstar/)

\section{Procedure}

See Figure 2 for a summary of principal steps for the analysis of transcriptional profiling of single 
myofibers.

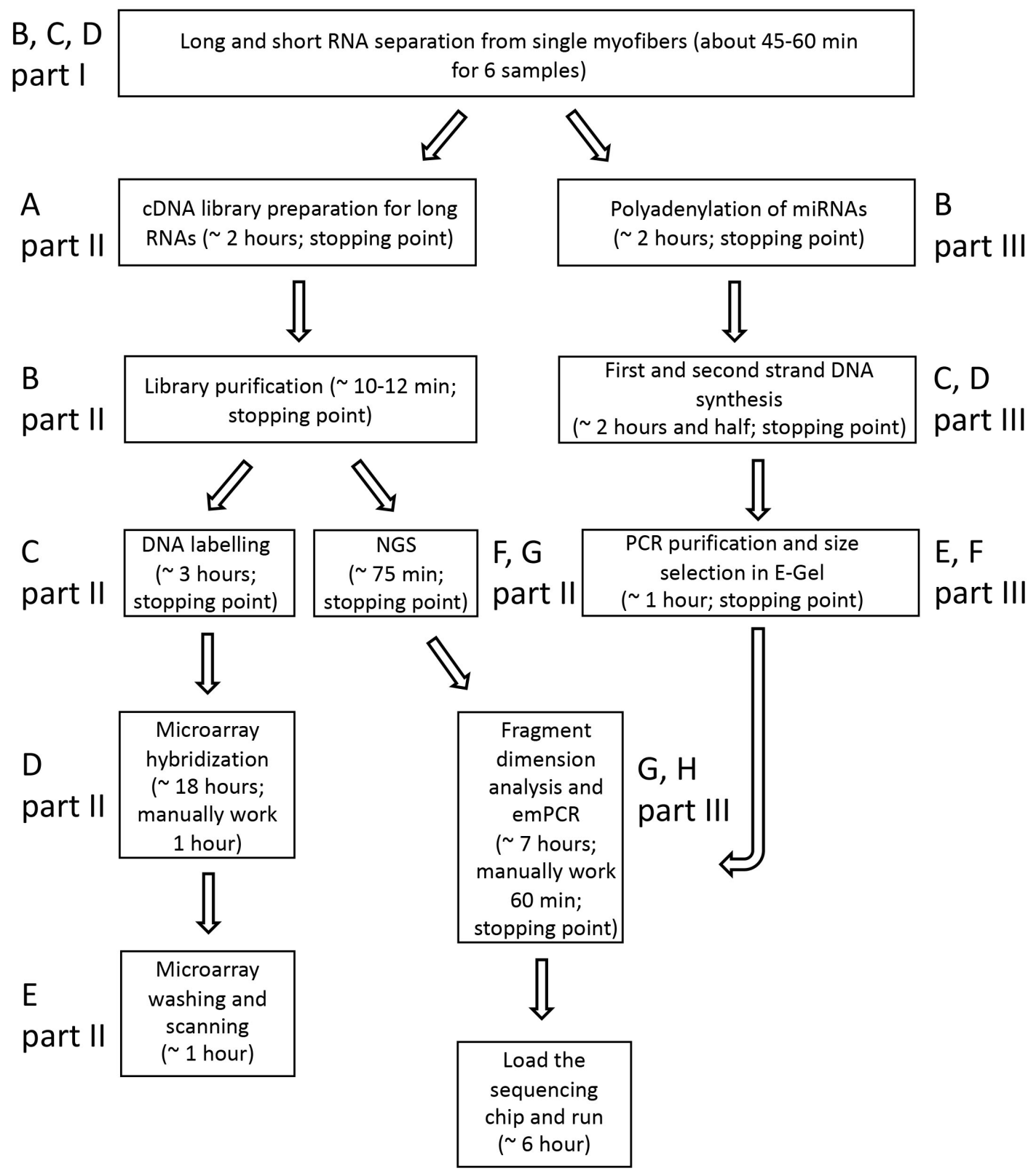

Figure 2. Workflow of transcriptomic analysis of single myofibers. The scheme summarizes principal steps for transcriptomic analysis of single myofibers. On the side of each box, it is reported the corresponding part of the protocol.

Part I: Purification of long RNAs (mRNAs and IncRNAs) and short RNAs (miRNAs) from single isolated myofibers

A. Myofiber isolation

Note: Here we will describe myofiber isolation from soleus and Extensor Digitorum Longus (EDL) hindlimb muscles of 3 months old mice, but the same procedure can be used for other types of skeletal 
muscles optimizing the timing of collagenase dissociation. In principle, younger mice have smaller muscles, we suggest decreasing the time of collagenase incubation and the repetitions of triturating process with muscles of young mice, to avoid damage of myofibers. On the contrary, muscles of older mice have more connective tissue, it could be necessary increase the time of collagenase incubation and the repetitions of triturating process to obtain a sufficient number of single isolated myofibers for the following analyses. In any case, it is important to limit this step to avoid the alteration of gene expression and consequently cell pathways. Sacrifice mice according to the local animal welfare act.

1. Collect soleus or EDL muscles from hindlimb mouse, taking care to handle them only by their tendons to minimize mechanical damage of myofibers (Figure 3 ). We used 3 months old CD1 mice. Store them in $1 \mathrm{ml}$ of cold DMEM $3 \mathrm{mM}$ BDM. Muscles collection should take no more than half an hour. Below, step by step procedure to collect soleus and EDL muscles.

2. Peel off the leg skin to expose the hindlimb muscles.

3. Gently remove the fascia of the hindlimb muscles.

4. Position the mouse supine and expose the tendons of tibialis anterior (TA) and EDL.

5. Cut the distal TA tendon and use it to remove the TA muscle by cutting it at its proximal attachment.

6. Cut the distal EDL tendon and remove it through cutting the proximal EDL tendon.

7. Place the muscle in a tube containing $1 \mathrm{ml}$ of DMEM $3 \mathrm{mM}$ BDM.

8. Repeat Steps A5-A7 to collect the EDL of the other leg.

9. Place the mouse in prone position.

10. Cut the tendon of gastrocnemius muscle and use it to peel off the muscle until the exposure of the soleus tendon.

11. Cut the soleus tendon and use it to remove the soleus cutting the other end.

12. Place the muscle in a tube containing $1 \mathrm{ml}$ of DMEM $3 \mathrm{mM} \mathrm{BDM}$.

13. Repeat to collect the soleus of the other leg.
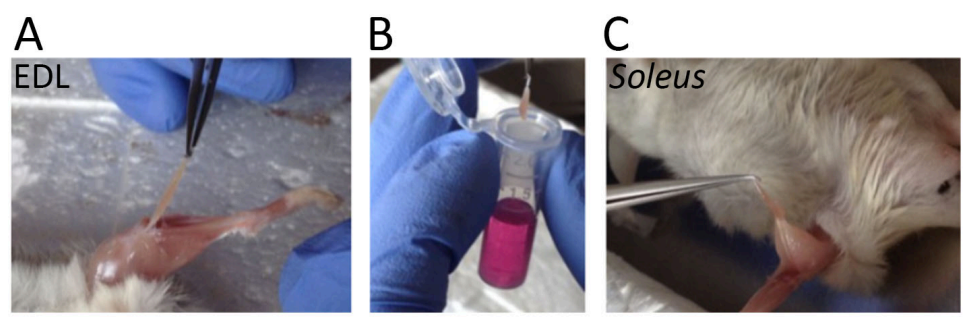

Figure 3. Muscles collection. A. EDL muscle isolated from hindlimb mouse muscles. B. Collection of one muscle in $1 \mathrm{ml}$ of DMEM $3 \mathrm{mM} \mathrm{BDM}$. C. Soleus muscle isolated from hindlimb mouse muscles.

14. Digest the muscles for $45 \mathrm{~min}$ at $37^{\circ} \mathrm{C}$ in $1 \mathrm{ml}$ high-glucose DMEM $3 \mathrm{mM}$ BDM containing $10 \mathrm{mg}$ type I collagenase in one well of a 24-well plate.

15. Sequentially rinse the muscles for $2 \mathrm{~min}$ in $3 \mathrm{ml}$ of DMEM and $3 \mathrm{mM} \mathrm{BDM}, 3 \mathrm{ml}$ DMEM and $3 \mathrm{mM}$ BDM supplemented with $10 \%$ FBS and $3 \mathrm{ml}$ of DMEM and $3 \mathrm{mM}$ BDM in different wells of a 6well plate (Figures 4A, 4B and 4C). Handle muscle with care and control under the microscope 
to avoid losing myofibers during these washing steps.

16. Transfer the muscles into a well of 6 -well plate with $3 \mathrm{ml}$ of DMEM with $10 \%$ FBS at about $25^{\circ} \mathrm{C}$ to inactivate collagenase (Figure 4D).

17. Liberate myofibers by gentle physical trituration (pipetting up and down) using a wide-mouth plastic Pasteur pipette (about $4 \mathrm{~mm}$ diameter), rinsed in FBS to prevent sticking.

18. Repeat the triturating process several times, eventually transferring non-dissociated muscle in new wells, until about 100 intact fibers are obtained. After each physical trituration, transfer the muscles into a new well, to get rid of collagen wisps and hyper-contracted fibers (Figures 4E, 4F, and $4 G)$.

19. Using a stereo-microscope and a micropipette $(200 \mu \mathrm{l}$ tips $)$, pick one by one intact and wellisolated fibers and wash first in a well with DMEM 3 mM BDM 10\% FBS and then in a well with PBS (Figure 4H).

20. If the researcher chose to avoid the myofiber characterization via MyHC protein expression (possible on a piece of myofiber [Chemello et al., 2011]), after washing, transfer the single myofiber into an RNase/DNase free Eppendorf microcentrifuge tube. The expression of specific genes [Myosin Heavy Chain 4 (Myh4), Myosin Light Chain 3 (Myl3), Myosin Heavy Chain 7 (Myh7), Tropomyosin 3 (Tpm3), actinin alpha 3 (Actn3), myosin heavy chain 2 (Myh2)] will be useful for the myofiber characterization (Chemello et al., 2019). See Figure 5 for the flowchart and timing specifications for each step.
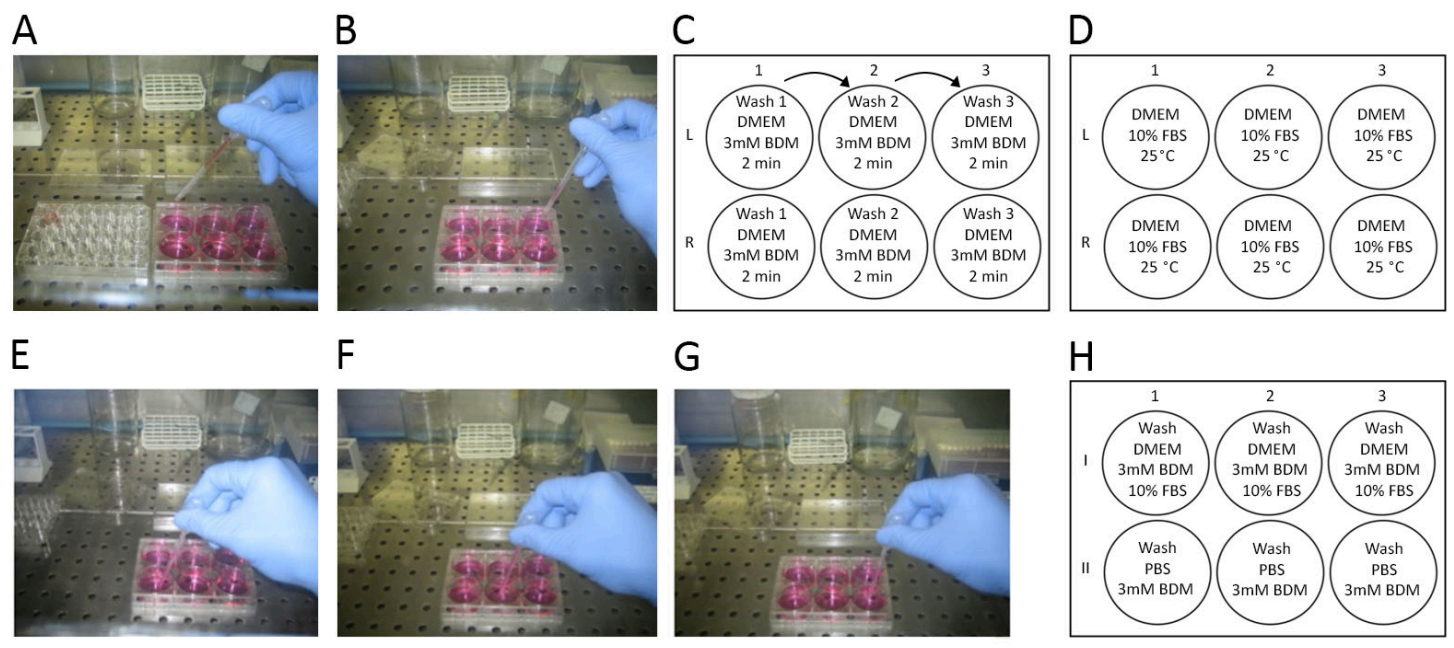

Figure 4. Steps for single myofiber dissociation and isolation. A. After $45 \mathrm{~min}$ of incubation with collagenase the muscle is transferred from a 24-well plate (on the left of the picture) into a well of a 6 -well plate containing $3 \mathrm{ml}$ of DMEM $3 \mathrm{mM}$ BDM. After $2 \mathrm{~min}$ of incubation, the whole muscle is transferred into the second well and then in the third well, waiting 2 min for the incubation in each well. B. Representation of the third transfer of the muscle. C. Scheme of the plate to use for the muscle rinsing after collagenase digestion ( $L$ : muscle form the left hindlimb; R: muscle from the right hindlimb; 1, 2, 3: first, second, and third wash). D. Scheme of the plate for collagenase inactivation and muscle dissociation $(1,2,3$ : steps for releasing single myofibers 
from muscle). E. Using a 6-well plate filled as described in D dissociate muscle during collagenase inactivation. F. Transfer the muscle not dissociated in the second well to leave free myofibers in the first one. G. Transfer the muscle not dissociated in the third well to leave free myofibers in the second well and liberate eventually other myofibers. Recover free myofibers from all the wells and transfer them into a new 24-well plate filled as described in $\mathrm{H}$. H. Scheme of the plate used to wash single myofibers (I: first wash; II: second wash; 1, 2, 3: several wells to wash different myofibers. It is not necessary to use a well per myofiber). After the second wash, single myofibers can be collected independently in different Eppendorf tubes or can be cut into two pieces; one used for their characterization using $\mathrm{MyHC}$ proteins and the other for RNA extraction and transcriptional analyses.

$1 \mathrm{~A}$ Muscle collection (about 10 min to collect Sol and EDL from both posterior legs)

$2 \mathrm{~A}$ Enzymatic dissociation using collagenase treatment (45 $\mathrm{min}$ )

$3 A$ Muscles washes (about 8-10 min)

$4-5-6 \mathrm{~A}$

Myofiber separation (2-4 $\mathrm{min})$

$7 \mathrm{~A}$

\begin{tabular}{|c|}
\hline $\begin{array}{c}\text { Myofibers collection under the inverted microscope (1-30 min } \\
\text { depending on how many fibers have to be collected) }\end{array}$ \\
\hline
\end{tabular}

$8 \mathrm{~A}$

\begin{tabular}{l} 
Use a myofiber fragment for its \\
typization according to the \\
expression of MyHC isoforms \\
\hline
\end{tabular}

Use the entire myofiber for RNA
extraction if its typization will be
performed according to the
expression of specific genes, or use
the remaining piece from the analysis
of MyHC protein isoforms to perform
gene expression analysis

Figure 5. Workflow for the isolation of single myofibers from hindlimb mouse muscles.

Each box describes work steps and timing and is associated with the protocol points. 
Note: During the isolation of single myofibers it is mandatory to follow exactly the same procedure and time points when processing the same muscle types derived from different mice to avoid introducing errors due to tissue processing. Moreover, it is important to avoid recovering contracted fibers to avoid having a different gene expression due to their peculiar condition. There are no stopping points during the myofiber collection procedure. Only when myofibers are lysed in TRIzol for RNA analysis, in Laemmli buffer (Tris pH $6.862 .5 \mathrm{mM}$, glycerol 10\%, SDS 2\%, $\beta$ mercaptoethanol 5\%) for MyHC analysis (Chemello et al., 2011), flash freeze in nitrogen and then the tube can be stored at $-80{ }^{\circ} \mathrm{C}$. In Figure $1 \mathrm{C}$, it is represented how isolated myofibers appear under microscope.

B. Long RNA and short RNA separation using RNeasy kits (Qiagen)

To proceed with RNA purification, it is better to avoid working with too many myofibers. We suggest working with 4-6 myofiber samples.

1. Lyse each myofiber in $250 \mu \mathrm{l}$ of TRIzol Reagent (Thermo Fisher Scientific) pipetting up and down the solution.

2. Add $50 \mu \mathrm{l}$ of chloroform, mix well by inverting the tube, and incubate on ice for $15 \mathrm{~min}$.

3. Centrifuge the sample for $15 \mathrm{~min}$ at $12,000 \times \mathrm{g}$ at $4{ }^{\circ} \mathrm{C}$.

4. Collect and transfer the aqueous upper phase (about $130 \mu l)$ into a new tube.

5. Add 1 volume of $70 \%$ ethanol and mix.

6. Transfer the solution onto a miRNeasy column (Qiagen).

7. Spin for $15 \mathrm{~s}$ at $12,000 \times \mathrm{g}$.

8. Long RNAs are retained by the column, whereas short RNAs are collected in the eluate. Retain the eluate and process as described in Section $D$ in Part I if you are interested in miRNA components.

C. Long RNA purification

1. Add $700 \mu \mathrm{l}$ of RWT Buffer (Qiagen) to the column containing long RNAs (Section B in Part I).

2. Spin for $15 \mathrm{~s}$ at $\geq 8,000 \times g$ and discard the eluate.

3. Add $500 \mu \mathrm{l}$ of RPE Buffer (Qiagen) to the column.

4. Spin for $15 \mathrm{~s}$ at $\geq 8,000 \times g$ and discard the eluate.

5. Add again $500 \mu \mathrm{l}$ of RPE Buffer (Qiagen) to the column.

6. Spin for $15 \mathrm{~s}$ at $\geq 8,000 \times g$ and discard the eluate.

7. Place the column in a new collection tube.

8. Add $50 \mu \mathrm{l}$ of nuclease-free water to the center of the column and incubate at room temperature for 2 min.

9. Spin for $1 \mathrm{~min}$ at $\geq 8,000 \times \mathrm{g}$ to eluate long RNAs. Eventually, store the eluate at $-80{ }^{\circ} \mathrm{C}$ in the eluted volume.

10. Use SpeedVac concentrator to reduce the volume to $14 \mu \mathrm{l}$. It is better to control the volume during its reduction to avoid drying the sample. 
11. Store at $-80^{\circ} \mathrm{C}$ until use. To avoid RNA binding to the plastic tube it is strongly suggested to use LoBind tubes.

D. miRNA purification using miRNeasy kit (Qiagen)

1. Add 0.65 volumes of absolute ethanol (about $165 \mu \mathrm{l}$ ) to the eluate produced after loading the aqueous phase of the TRIzol extraction into the miRNeasy columns (Section B in Part I) and mix well.

2. Transfer the solution onto an RNeasy micro column (Qiagen).

3. Spin for $15 \mathrm{~s}$ at $\geq 8,000 \times \mathrm{g}$ and discard the eluate.

4. Add $500 \mu \mathrm{l}$ of RPE Buffer (Qiagen) to the column.

5. Spin for $15 \mathrm{~s}$ at $\geq 8,000 \times g$ and discard the eluate.

6. Add $500 \mu \mathrm{l}$ of $80 \%$ ethanol to the column.

7. Spin for $2 \mathrm{~min}$ at $\geq 8,000 \times g$ and discard the eluate.

8. Spin again for $5 \mathrm{~min}$ at $\geq 8,000 \times g$ with the cap opened.

9. Transfer the column to a new collection tube.

10. Add $14 \mu \mathrm{l}$ of nuclease-free water to the center of the column and incubate at room temperature for 2 min.

11. Spin for $1 \mathrm{~min}$ at $\geq 8,000 \times g$ to eluate miRNAs. Eventually, store the eluate at $-80^{\circ} \mathrm{C}$ in the eluted volume.

12. Use SpeedVac concentrator to reduce the volume to $6.5 \mu \mathrm{l}$. If you dry the solution, resuspend miRNAs in nuclease-free water and preferably use LoBind tubes for the SpeedVac step.

13. Store at $-80^{\circ} \mathrm{C}$ until use.

Part II: Transcriptomic profiling of long RNAs from single isolated myofibers by microarray

A. Preparation of the cDNA library of long RNAs for microarray hybridization using Complete Whole Transcriptome Amplification Kit (Sigma)

1. Add $2.5 \mu \mathrm{l}$ of Library Synthesis Solution to the $14 \mu \mathrm{l}$ of long RNA solution prepared in Section C in Part I.

2. Incubate at $70^{\circ} \mathrm{C}$ for $5 \mathrm{~min}$ and cool down the temperature by putting the Eppendorf on ice $\left(\sim 4^{\circ} \mathrm{C}\right)$ for 5 min.

3. Add the mix indicated below to the solution previously prepared (Steps A1 and A2 in Part II) (Table 1).

Table 1. Library synthesis enzyme mix

\begin{tabular}{ll}
\hline Reagent & Volume \\
\hline Library Synthesis Buffer & $2.5 \mu \mathrm{l}$ \\
Library Synthesis Enzyme & $2.0 \mu \mathrm{l}$ \\
Nuclease-free water & $3.9 \mu \mathrm{l}$ \\
\hline
\end{tabular}


4. Incubate in the thermocycler using the parameters shown in (Table 2).

Table 2. Parameters for library synthesis

\begin{tabular}{ll}
\hline Temperature & Time \\
\hline $18{ }^{\circ} \mathrm{C}$ & $10 \mathrm{~min}$ \\
$25^{\circ} \mathrm{C}$ & $10 \mathrm{~min}$ \\
$37^{\circ} \mathrm{C}$ & $30 \mathrm{~min}$ \\
$42^{\circ} \mathrm{C}$ & $10 \mathrm{~min}$ \\
$70^{\circ} \mathrm{C}$ & $20 \mathrm{~min}$ \\
$4{ }^{\circ} \mathrm{C}$ & hold \\
\hline
\end{tabular}

5. Remove tubes from the thermocycler and spin briefly.

6. Add the mix indicated into the solution (Table 3).

Table 3. Library amplification solution

\begin{tabular}{ll}
\hline Reagent & Volume \\
\hline Amplification Mix & $37.5 \mu \mathrm{l}$ \\
WTA dNTP Mix & $7.5 \mu \mathrm{l}$ \\
Amplification Enzyme & $3.75 \mu \mathrm{l}$ \\
Nuclease-free water & $301 \mu \mathrm{l}$ \\
\hline
\end{tabular}

7. Divide previously prepared mix into five Eppendorf each containing $75 \mu \mathrm{l}$ of solution (for the last aliquot the reaction volume is $<75 \mu \mathrm{l}$ ).

8. Incubate in the thermocycler using the following parameters (Table 4).

Table 4. Parameters for Library amplification

\begin{tabular}{lll}
\hline Temperature & Time & Cycles \\
\hline $94{ }^{\circ} \mathrm{C}$ & $2 \mathrm{~min}$ & \\
$94{ }^{\circ} \mathrm{C}$ & $30 \mathrm{~s}$ & 18 \\
$70^{\circ} \mathrm{C}$ & $5 \mathrm{~min}$ & \\
$4{ }^{\circ} \mathrm{C}$ & hold & \\
\hline
\end{tabular}

9. Store the WTA DNA at $-20^{\circ} \mathrm{C}$ until use.

B. WTA DNA purification using GenElute PCR Clean-Up Kit (Sigma)

1. Purify separately each mix (each Eppendorf contains $75 \mu \mathrm{l}$ of solution prepared as described in Section A of Part II).

2. Add $375 \mu \mathrm{l}$ of Binding Solution and transfer the solution into the binding column.

3. Spin for $1 \mathrm{~min}$ at $12,000 \times \mathrm{g}$ and discard the eluate. 
4. Add $500 \mu \mathrm{l}$ of Wash Solution to the column.

5. Spin for $1 \mathrm{~min}$ at $12,000 \times \mathrm{g}$ and discard the eluate.

6. Spin for 2 min at maximum speed without any additional wash.

7. Transfer the column to a new collection tube.

8. Add $50 \mu \mathrm{l}$ of nuclease-free water to the center of the column and incubate at room temperature for 2 min

9. Spin for $1 \mathrm{~min}$ at $12,000 \times \mathrm{g}$.

10. Quantify DNA using Nanodrop spectrophotometer.

11. Store the purified WTA DNA at $-20^{\circ} \mathrm{C}$ until use.

12. WTA DNA can be labeled for microarray hybridization (Section $C$ in Part II) or can be used for NGS library preparation (Section F in Part II).

C. Labeling WTA DNA for microarray hybridization using SureTag DNA Labeling Kit (Agilent)

1. Prepare $2 \mu \mathrm{g}$ of WTA DNA in $13 \mu \mathrm{l}$ of nuclease-free water.

2. Add $2.5 \mu$ of Random Primers.

3. Incubate at $98^{\circ} \mathrm{C}$ for $5 \mathrm{~min}$.

4. Move onto ice and incubate for $5 \mathrm{~min}$.

5. Spin for $1 \mathrm{~min}$ at $12,000 \times \mathrm{g}$.

6. Add the mix indicated to the solution (Table 5).

Table 5. DNA labeling solution

\begin{tabular}{ll}
\hline Reagent & Volume \\
\hline 5x Reaction Buffer & $5.0 \mu \mathrm{l}$ \\
10x dNTPs & $2.5 \mu \mathrm{l}$ \\
Cy3-dUTP & $1.5 \mu \mathrm{l}$ \\
Exo (-) Klenow & $0.5 \mu \mathrm{l}$ \\
\hline
\end{tabular}

7. Incubate in the thermocycler using the parameters shown in Table 6 .

Table 6. Parameters for DNA labeling

\begin{tabular}{ll}
\hline Temperature & Time \\
\hline $37^{\circ} \mathrm{C}$ & $2 \mathrm{~h}$ \\
$35^{\circ} \mathrm{C}$ & $10 \mathrm{~min}$ \\
$4{ }^{\circ} \mathrm{C}$ & hold \\
\hline
\end{tabular}

8. Spin for $1 \mathrm{~min}$ at $10,000 \times \mathrm{g}$.

9. Add $430 \mu \mathrm{l} 1 \times \mathrm{TE}(\mathrm{pH} 8.0)$.

10. Transfer the solution onto a purification column provided with the SureTag DNA Labeling Kit (Agilent). 
11. Spin for $10 \mathrm{~min}$ at $14,000 \times g$ and discard the eluate.

12. Add $480 \mu \mathrm{l}$ of $1 \times \mathrm{TE}(\mathrm{pH} 8.0)$ to the column.

13. Spin for $10 \mathrm{~min}$ at $14,000 \times g$ and discard the eluate.

14. Invert the column into a new tube.

15. Spin for $1 \mathrm{~min}$ at $1,000 \times g$ to collect the purified sample. The volume per sample will be approximatively $20-32 \mu \mathrm{l}$.

16. Measure DNA quantity and labeling using Nanodrop spectrophotometer. DNA yield will be about $4 \mu \mathrm{g}$ and the specific activity $30 \mathrm{pmol}$ of Cy3 per $\mu \mathrm{g}$ of cDNA.

17. Store the labeled DNA at $-20^{\circ} \mathrm{C}$ until use.

D. Hybridization on Agilent microarrays

Note: If you are interested in measuring the expression of IncRNAs make sure that the microarray platform you are using contains probes for this class of transcripts.

1. Prepare $800 \mathrm{ng}$ of labeled DNA in $20 \mu \mathrm{l}$ of nuclease-free water.

2. Add $5 \mu \mathrm{l}$ of $10 x$ Blocking Agent.

3. Incubate at $95^{\circ} \mathrm{C}$ for $2 \mathrm{~min}$.

4. Add $25 \mu$ l of $2 x$ GEx Hybridization Buffer HI-RPM.

5. Dispense $40 \mu \mathrm{l}$ of the solution on hybridization gasket slide.

6. Put the $8 \times 60 \mathrm{~K}$ microarray platform slide facing down the hybridization gasket slide.

7. Load the microarray sandwich into the Agilent SureHyb chamber.

8. Load the assembled chamber into the oven rotator rack.

9. Hybridize at $65^{\circ} \mathrm{C}$ for $17 \mathrm{~h}$ at $10 \mathrm{rpm}$.

E. Scan of the microarray slides

1. Disassemble the hybridization chamber.

2. Disassemble the microarray sandwich in slide-staining dish filled with Wash Buffer 1.

3. Wash the microarray slide in Wash Buffer 1 for $1 \mathrm{~min}$.

4. Wash the microarray slide in $37^{\circ} \mathrm{C}$ pre-warmed Wash Buffer 2 for $1 \mathrm{~min}$.

5. Slowly remove the microarray slide, to minimize droplets on the slide.

6. Put the microarray slide in a slide holder.

7. Scan the slide using $\mathrm{G} 2505 \mathrm{C}$ scanner at $3 \mu \mathrm{m}$ resolution to obtain single myofiber mRNA and IncRNA expression profile.

F. NGS of RNA extracted from a single myofiber

1. The bulk of SeqPlex amplification product (WTA DNA) ranges in size from 200-400 base pairs and therefore it is not needed DNA fragmentation for its sequencing. Here we will describe the sequencing protocol to use Ion Torrent or Proton sequencers but changing adapters, amplified RNA (WTA DNA) can also be sequenced with Illumina sequencer.

2. The terminus of each amplicon possesses a 5'-phosphate and 2-base 3'-over-hang. 
G. Sequencing library preparation

1. In a $0.2 \mathrm{ml} \mathrm{PCR}$ tube, prepare Adapters mix as indicated in the table below (non-barcoded), and mix by pipetting up and down. Reagents are in the Ion Xpress Plus gDNA Library preparation (Thermo Fisher Scientific) (Table 7).

Table 7. Adapters mix

\begin{tabular}{ll}
\hline Reagent & Volume \\
\hline Adapters & $3 \mu \mathrm{l}$ \\
Nuclease-free water & $9 \mu \mathrm{l}$ \\
Total volume & $\mathbf{1 2 \mu l}$ \\
\hline
\end{tabular}

2. Prepare the following mix (Table 8).

Table 8. DNA repair and adapters ligation mix

\begin{tabular}{ll}
\hline Reagent & Volume \\
\hline WTA DNA & X $\mu \mathrm{l}(1 \mu \mathrm{g})$ \\
10x Ligase Buffer & $10 \mu \mathrm{l}$ \\
Adapters mix from Step G1 in Part II & $10 \mu \mathrm{l}$ \\
dNTP Mix & $2 \mu \mathrm{l}$ \\
Nuclease-free water & $41 \mu \mathrm{l}$ \\
DNA Ligase & $4 \mu \mathrm{l}$ \\
Nick Repair Polymerase & $8 \mu \mathrm{l}$ \\
Total volume & $\mathbf{1 0 0 \mu l}$ \\
\hline
\end{tabular}

3. Incubate in thermal cycler following the program below (Table 9).

Table 9. Parameters for DNA repair and adapters ligation

\begin{tabular}{lll}
\hline Stage & Temperature & Time \\
\hline Hold & $25^{\circ} \mathrm{C}$ & $15 \mathrm{~min}$ \\
Hold & $72{ }^{\circ} \mathrm{C}$ & $5 \mathrm{~min}$ \\
Hold & $4{ }^{\circ} \mathrm{C}$ & Hold \\
\hline
\end{tabular}

4. Purify adapter-ligated DNA using Agencourt AMPure XP beads.

According to the desired reads length it will be used different amounts of Agencourt AMPure XP beads: add $100 \mu \mathrm{l}$ of Agencourt AMPure XP beads to $100 \mu \mathrm{l}$ of reaction from Step G3 in Part II for 400-600 bp reads length, $120 \mu \mathrm{l}$ of Agencourt AMPure XP beads to $100 \mu \mathrm{l}$ of reaction from Step G3 in Part II for 200-300 bp reads length.

5. Mix well by pipetting up and down and avoid bubble formation. Then place the tube in a magnetic rack (e.g., DynaMag) for 3 min and wait until the solution becomes clear. 
6. Discard the supernatant and avoid disturbing the pellet.

7. Add $500 \mu$ of freshly prepared $70 \%$ ethanol leaving the tube on the magnet.

8. Incubate for $30 \mathrm{~s}$ rotating the tube around the vertical axis 3 times and maintaining the tube on the magnet to agitate the beads avoiding that they go in the solution. After the solution is clear, remove the supernatant avoiding disturbing the pellet.

9. Wash the beads with $70 \%$ ethanol for a second time as indicated in the previous step.

10. Remove residual of ethanol centrifuging the tube, placing it on the magnet and pipetting out the supernatant using a tip for a P10 micropipette.

11. Keep the cap-opened tube on the magnet for $5 \mathrm{~min}$ to air dry the beads (avoid over dry).

12. Remove the tube from the magnet, add $20 \mu \mathrm{l}$ of Low TE on the beads and mix by pipetting up and down the solution. Vortex the sample for $10 \mathrm{~s}$.

13. Spin the solution for a few seconds and place the tube on the magnet for at least 1 min.

14. Transfer the supernatant into a new LoBind Eppendorf without disturbing the pellet.

15. Store at $-30{ }^{\circ} \mathrm{C}$ to $-10{ }^{\circ} \mathrm{C}$.

16. Before performing emulsion-PCR, amplification library can or cannot be selected in a gel according to DNA size. If the range selected with Agencourt AMPure XP beads it is fine for NGS researcher to go throughout emPCR. For method about size selection see Section F in Part III. For emulsion-PCR, see Section H in Part III.

\section{Part III: Transcriptomic profiling of miRNAs from single isolated myofibers by NGS}

A. Purification of miRNAs from a single myofiber (see Section D in Part I)

B. Polyadenylation of miRNAs using Poly(A) Tailing Kit (Thermo Fisher Scientific)

1. Add the mix indicated in Table 10 to the solution of miRNAs purified as in Section D in Part I (6.5 $\mu$ l of miRNA solution).

Table 10. Poly(A) tailing mix

\begin{tabular}{ll}
\hline Reagent & Volume \\
\hline Purified miRNAs & $6.5 \mu \mathrm{l}$ \\
$5 x$ E-PAP Buffer & $2.0 \mu \mathrm{l}$ \\
$\mathrm{MnCl}_{2}[25 \mathrm{mM}]$ & $1.0 \mu \mathrm{l}$ \\
ATP $[10 \mathrm{mM}]$ & $0.5 \mu \mathrm{l}$ \\
E-PAP Enzyme & $0.5 \mu \mathrm{l}$ \\
Total volume & $\mathbf{1 0 . 5} \boldsymbol{\mu l}$ \\
\hline
\end{tabular}

2. Incubate at $37^{\circ} \mathrm{C}$ for $1 \mathrm{~h}$.

3. Add $1 \mu \mathrm{l} \mathrm{NaOAc} 3 \mathrm{M}$ (pH 5.5).

4. Add $44 \mu \mathrm{l}$ of absolute ethanol and mix well. 
5. Precipitate at $-20^{\circ} \mathrm{C}$ overnight.

6. Spin for $20 \mathrm{~min}$ at maximum speed and carefully remove the supernatant without disturbing the pellet.

7. Wash with $50 \mu \mathrm{l}$ of $75 \%$ ethanol.

8. Spin for $10 \mathrm{~min}$ at maximum speed and carefully remove the supernatant without disturbing the pellet.

9. Resuspend in $3.2 \mu \mathrm{l}$ of nuclease-free water.

C. Synthesis of the first stranded cDNA from polyadenylated miRNAs (from Section B in Part III)

1. Prepare the mix A in a $0.2 \mathrm{ml}$ tube as indicated in Table 11.

Table 11. Retrotranscription mix A

\begin{tabular}{|c|c|}
\hline Reagent & Volume \\
\hline dNTP Mix [10 mM] & $0.5 \mu \mathrm{l}$ \\
\hline 5x First Strand Buffer & $1 \mu \mathrm{l}$ \\
\hline $0.1 \mathrm{M} \mathrm{DTT}$ & $1 \mu \mathrm{l}$ \\
\hline RNase OUT [40 U/Ml] & $1 \mu \mathrm{l}$ \\
\hline SuperScript II RT [200 U/ul] & $0.5 \mu \mathrm{l}$ \\
\hline Nuclease free water & $1 \mu \mathrm{l}$ \\
\hline Total volume & $5 \mu \mathrm{l}$ \\
\hline
\end{tabular}

2. Prepare the mix B in a $0.2 \mathrm{ml}$ tube as indicated below (Table 12).

Table 12. Retrotranscription mix B

\begin{tabular}{ll}
\hline Reagent & Volume \\
\hline Polyadenylated miRNAs (from Section B in Part III) & $3.2 \mu \mathrm{l}$ \\
$\begin{array}{l}\text { Oligo-dT-lon P1 adapter primer [60 } \mu \mathrm{M}] \\
\left(5^{\prime}-\text {-CCTCTCTATGGGCAGTCGGTGATCCTCAGC[dT]20VN-3') }\right.\end{array}$ & $1 \mu \mathrm{l}$ \\
$\begin{array}{l}\text { SMART primer [10 } \mu \mathrm{M}] \\
\left(5^{\prime}-\text {-CACACACAATTAACCCTCACTAAAggg-3' lower case letters are }\right. \\
\text { ribonucleic bases) }\end{array}$ & $0.8 \mu \mathrm{l}$ \\
$\begin{array}{l}\text { Total volume } \\
\end{array}$ & $\mathbf{5 \mu l}$ \\
\hline
\end{tabular}

3. Incubate the mix B at $65^{\circ} \mathrm{C}$ for 5 min in a thermoblock or thermocycler without heated lid.

4. Spin the mix $B$ and incubate it on ice for $5 \mathrm{~min}$.

5. Mix the mix A and B. You should have a final volume of $10 \mu$ l. Mix well the solution by pipetting up and down.

6. Incubate at $42^{\circ} \mathrm{C}$ for 60 min using a thermocycler without heated lid.

7. Inactivate the enzyme at $70{ }^{\circ} \mathrm{C}$ for $15 \mathrm{~min}$. 
D. Synthesis of the second stranded cDNA

Second strand cDNA is synthesized by a PCR step avoiding reaching the plateau phase. In fact, it is important to maintain the original ratios of miRNAs. This step allows the production of double stranded DNA that, after its purification, can be sequenced because presenting on the $5^{\prime}$ and $3^{\prime}$ end sequencing primers for the lon Torrent platform. It is important to use a High-Fidelity Taq DNA polymerase to avoid the introduction of errors during PCR amplification. For a scheme of the SMART protocol see Figure 6.

1. Prepare the following mix to perform two PCR reactions per sample (each of $50 \mu \mathrm{l}$ ) (Table 13).

Table 13. PCR amplification of poly(A) tagged miRNAs

\begin{tabular}{|c|c|}
\hline Reagent & Volume \\
\hline Buffer 10x High Fidelity & $5 \mu \mathrm{l}$ \\
\hline $\mathrm{MgSO}_{4}[50 \mathrm{mM}]$ & $2 \mu \mathrm{l}$ \\
\hline dNTPs [10 mM] & $1 \mu \mathrm{l}$ \\
\hline Primer $\mathrm{A}[10 \mu \mathrm{M}]$ & \multirow{3}{*}{$1 \mu \mathrm{l}$} \\
\hline (5'-CСАTCTCATCCСТGCGTGTCTCCGACTCAGCACACACAATTAACCC & \\
\hline $\begin{array}{l}\text { TCACTAAAGGG-3' underlined the sequence of the Smart primer and not } \\
\text { underlined the sequence of adaptor A for NGS sequencing) }\end{array}$ & \\
\hline Primer P1 [10 $\mu \mathrm{M}$ ] (5'-CCTCTCTATGGGCAGTCGGTGATCCTCAGC-3') & $1 \mu \mathrm{l}$ \\
\hline cDNA from Section C in Part III & $1 \mu \mathrm{l}$ \\
\hline Platinum DNA polymerase High Fidelity $5 \mathrm{U} / \mu \mathrm{l}$ & $0.25 \mu \mathrm{l}$ \\
\hline Nuclease free water & $38.75 \mu \mathrm{l}$ \\
\hline Total volume & $50 \mu \mathrm{l}$ \\
\hline
\end{tabular}

2. Incubate in the thermocycler according to the following cycle (Table 14).

Table 14. Parameters for PCR amplification of poly(A) tagged miRNAs

\begin{tabular}{lll}
\hline Temperature & Time & Cycles \\
\hline $95{ }^{\circ} \mathrm{C}$ & $30 \mathrm{~s}$ & \\
$95{ }^{\circ} \mathrm{C}$ & $20 \mathrm{~s}$ & $10-12$ \\
$55^{\circ} \mathrm{C}$ & $10 \mathrm{~s}$ & \\
$72{ }^{\circ} \mathrm{C}$ & $40 \mathrm{~s}$ & \\
$72{ }^{\circ} \mathrm{C}$ & $5 \mathrm{~min}$ & \\
$4{ }^{\circ} \mathrm{C}$ & Hold & \\
\hline
\end{tabular}



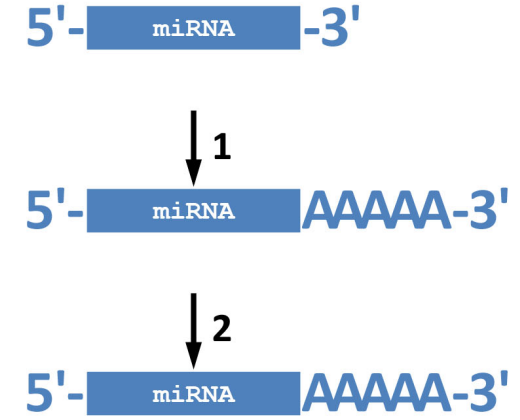

3'-TTTTTIIon P1 Adapters-5'

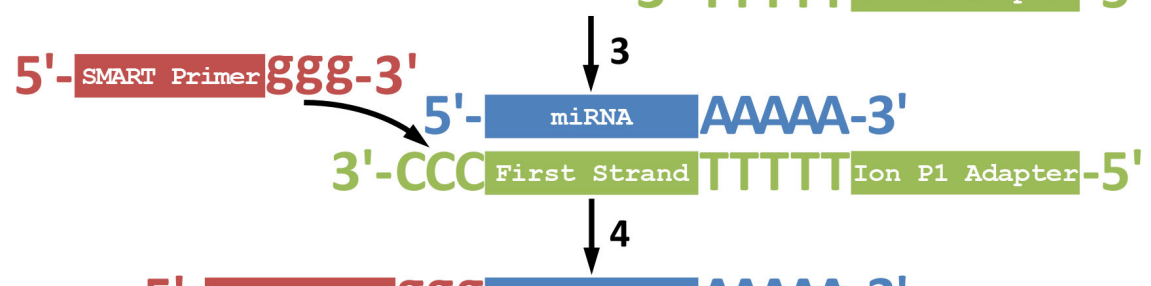

5'-SVMART Primerggg miRNA AAAAA-3'

3'-First strand CCC First strand TTTTTIIon P1 Adapter-5'

$\downarrow 5$

5"-Ion A Adapter SWART Primer GGG-3"

$3^{\prime}$-First strand CCC First strand TTTTTIIon P1 Adapter-5'

16

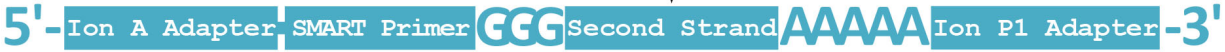

3'-First strand CCC First strand TTTTTIIon P1 Adapters-5'

$\downarrow 7$

5'-Ion A Adapter, SWRARr Priner GGG second StrandAAAAAIon P1 Adapter-3'

3'-Ion P1 Adapter-5'

18

$5^{\prime \prime-I o n ~ A ~ A d a p t e r ~ S M A R T ~ P r i m e r ~ G G G ~ S e c o n d ~ S t r a n d / M A A A I o n ~ P 1 ~ A d a p t e r-3 " ~}$

3'-Ion A Adapter First Strand CCC First Strand TTTTT Ion P1 Adapter-5'

Ion P1 Adapter: 5'-CCTCTCTATGGGCAGTCGGTGATCCTCAGC [dT] 20VN-3'

SMART Primer: 5'-CACACACAATTAACCCTCACTAAAggg-3'

Ion A Adapter: 5'-CCATCTCATCCCTGCGTGTCTCCGACTCAG-3'

Figure 6. Scheme for miRNA amplification. miRNAs extracted from a single myofiber are polyadenylated using the PAP enzyme (1, and Section B in Part III). After that, using the SMART technique (Wellenreuther et al., 2004) miRNAs are retrotranscribed. The primer used for the retrotranscription is an oligo-d(T) that includes the lon P1 adapter sequence at the $5^{\prime}$ end (2). When the Superscript II reaches the $5^{\prime}$ end of miRNA it adds a stretch of no template $C$ to the cDNA that serves for the binding of the SMART primer (3). In the SMART primer, the three terminal $g$ are RNA nucleotides. After the binding of the SMART primer to the cDNA it is used from the Superscript II for the synthesis of the complementary sequence (4, and Section C in Part III). 
Using this method, two anchors at the $3^{\prime}$ and $5^{\prime}$ end of the miRNAs are produced. The two anchors can be used for the miRNA amplification by PCR reaction. During PCR amplification (Section D in Part III) a specific primer it is used to include the A adapter in the $5^{\prime}$ end of miRNAs (5) that will be useful for miRNA sequencing in a strand specific way. After 10-12 cycles of PCR amplification $(6,7,8)$, sufficient quantity of double stranded DNA is obtained with P1 and A adaptors on the miRNA $3^{\prime}$ and $5^{\prime}$ end, respectively to allow emulsion-PCR and following sequencing.

E. DNA purification using GenElute PCR Clean-Up Kit (Sigma)

1. Pool the two PCRs $(50+50 \mu l)$. If you have more than one sample remember to maintain them separated.

2. Add $500 \mu \mathrm{l}$ of Binding Solution to the pooled PCRs and transfer the solution into the binding column.

3. Spin for $1 \mathrm{~min}$ at $12,000 \times g$ and discard the eluate.

4. Add $500 \mu \mathrm{l}$ of Wash Solution to the column.

5. Spin for $1 \mathrm{~min}$ at $12,000 \times \mathrm{g}$ and discard the eluate.

6. Spin for 2 min at maximum speed without any additional wash.

7. Transfer the column to a new collection tube.

8. Add $50 \mu \mathrm{l}$ of nuclease-free water to the center of the column and incubate at room temperature for 2 min.

9. Spin for $1 \mathrm{~min}$ at $12,000 \times \mathrm{g}$.

10. Quantify DNA using Nanodrop spectrophotometer.

11. Store the purified $\mathrm{PCR}$ at $-20^{\circ} \mathrm{C}$ until use.

F. Size selection for NGS using the E-Gel SizeSelect Gels (Thermo Fisher Scientific)

For DNA sequencing it is important to select the size range of DNA to be sequenced. In the case of long RNAs dimensional purification it was described in the Step G4 in Part II. Retained reads to identify miRNAs are 18-35 nt long (He et al., 2019) or purified small RNAs for miRNA libraries covers the same dimensional range ( Krishna et al., 2013; Fu et al., 2018) and adapters added during the library construction (Sections D and E in Part III) are $\sim 107$ nucleotides (Primer A is 57 nt and OligodT-Ion P1 50 nt ) (Figure 6). We, therefore, selected the smear between 125 and $142 \mathrm{nt}$. See below for the full procedure.

1. Use a $2 \%$ agarose gel.

2. Each well of the gel should be loaded with no more than 20-25 $\mu$ and 500 ng of DNA.

3. If DNA prepared from Section $E$ in Part III needed to be diluted use Low TE to dilute it.

4. Dilute DNA ladder (50 bp) to $25 \mathrm{ng} / \mu \mathrm{l}$ with Low TE and load central well of the E-Gel with $10 \mu \mathrm{l}$ of diluted ladder.

5. Load sample wells avoiding using adjacent wells for different samples (same samples split in different volumes can be loaded in adjacent wells).

6. Empty wells have to be filled with $25 \mu \mathrm{l}$ of nuclease-free water. 
7. Run E-Gel SizeSelect instrument (Thermo Fisher Scientific) selecting the correct program (SizeSelect 2\%).

8. Visualize the run using the instrument and stop it when desired DNA dimension filled recovery well.

9. Recover the solution from the recovery well using a P20 pipette without touching the gel. Usually, 12-15 $\mu \mathrm{l}$ can be recovered.

10. Fill the recovery well with nuclease-free water replacing the withdrawn volume.

11. Start again the instrument and repeat Step F9 in Part III until all the desired dimensional range is recovered.

G. Dimensional analysis and library quantification (Agilent Bioanalyzer analysis)

Run purified samples according to the High Sensitivity DNA Chip (Agilent).

1. Thaw High Sensitivity DNA kit at room temperature for at least 30 min.

2. Prepare gel dye mix by adding $15 \mu \mathrm{l}$ of High Sensitivity DNA dye to High Sensitivity DNA gel matrix.

3. Mix by vortexing and spin down.

4. Put the solution onto Spin-X Centrifuge tubes $0.22 \mu \mathrm{M}$ pore diameter (Corning Costar) and centrifuge at 2,200 $\mathrm{xg}$ for $10 \mathrm{~min}$ at room temperature.

5. Load the High Sensitivity DNA chip as described in the table below (Table 15).

Table 15. Agilent Bioanalyzer chip loading

\begin{tabular}{|c|c|}
\hline Well & Action \\
\hline & $\begin{array}{l}\text { Pipette } 9 \mu \mathrm{l} \text { of gel dye mix (prepared on Step G4 in Part III) in } \\
\text { indicated well, close the chip on the priming station and press the } \\
\text { syringe starting from the position of } 1 \mathrm{ml} \text { (do not aspirate when } \\
\text { the chip is closed in the priming station), lock the syringe and wait } \\
60 \mathrm{~s} \text {, unlock the siring after } 60 \mathrm{~s} \text {, wait } 10 \mathrm{~s} \text { or until the syringe } \\
\text { reached about the } 0.9 \mathrm{ml} \text { position, unlock the chip from the } \\
\text { priming station. }\end{array}$ \\
\hline G & Pipette $9 \mu \mathrm{l}$ of gel dye mix in indicated well. \\
\hline Sample and ladder wells & Pipette $5 \mu \mathrm{l}$ of marker. \\
\hline Ladder well & Pipette $1 \mu$ l of High Sensitivity DNA ladder. \\
\hline \multirow[t]{2}{*}{ Sample wells } & $\begin{array}{l}\text { Pipette } 1 \mu \mathrm{l} \text { of DNA sample and fill wells not filled with DNA } \\
\text { samples with } 1 \mu \mathrm{l} \text { of marker. There are } 11 \text { well available for } \\
\text { samples. }\end{array}$ \\
\hline & $\begin{array}{l}\text { Put the chip in the Agilent vortex and vortex at maximum speed } \\
\text { for } 1 \text { min Run the chip in the Agilent } 2100 \text { Bioanalyzer instrument } \\
\text { within } 5 \text { min. }\end{array}$ \\
\hline
\end{tabular}


6. From the Bioanalyzer analysis used to assess the library size distribution, determine the molar library concentration in $\mathrm{pmol} / \mathrm{L}$ using the Bioanalyzer software.

7. Determine the dilution factor that results in a concentration of the library of $\sim 100 \mathrm{pM}$.

8. This concentration is suitable for template preparation using lon OneTouch Template Kit (Thermo Fisher Scientific). Use the following formula: Dilution factor $=($ Library concentration in $\mathrm{pM}) / 100$ pM.

9. Dilute the library in a new LoBind Eppendorf using a small amount of DNA library and necessary Low TE to yield approximately a concentration of $100 \mathrm{pM}$. Use this library dilution for template preparation.

H. Emulsion-PCR (template preparation for DNA sequencing) using the lon OneTouch system (Thermo Fisher Scientific)

Note: Described material is included in the Ion PGM Hi-Q OT2 Kit (Thermo Fisher Scientific).

1. Set up the Ion OneTouch system.

2. Prepare the amplification solution as follow (Table 16).

Table 16. DNA library dilution

\begin{tabular}{ll}
\hline Reagent & Volume \\
\hline Diluted library [100 pM] & $2 \mu \mathrm{l}$ \\
Nuclease free water & $23 \mu \mathrm{l}$ \\
Total volume & $\mathbf{2 5 \mu l}$ \\
\hline
\end{tabular}

3. Vortex for $5 \mathrm{~s}$ and spin for $2 \mathrm{~s}$.

4. Prepare the lon PGM Hi-Q ISPs and mix thoroughly by vortexing the tube for 1 min and spinning for $2 \mathrm{~s}$.

5. Prepare the following mix in a 2-ml LoBind tube (Table 17).

Table 17. OneTouch reaction mix

\begin{tabular}{ll}
\hline Reagent & Volume \\
\hline lon PGM Hi-Q Reagent Mix & $800 \mu \mathrm{l}$ \\
Nuclease free water & $25 \mu \mathrm{l}$ \\
lon PGM Hi-Q Enzyme mix & $50 \mu \mathrm{l}$ \\
Diluted library from Step H2 in Part III & $25 \mu \mathrm{l}$ \\
lon PGM Hi-Q ISPs & $100 \mu \mathrm{l}$ \\
Total volume & $\mathbf{1 , 0 0 0 \mu l}$ \\
\hline
\end{tabular}

6. Load the Ion OneTouch Reaction Filter with the solution prepared in Step H5 of Part III, install the filter onto the lon OneTouch Instrument and start the run.

7. At the end of the run, enrich for the template-positive IPSs following the lon OneTouch instructions 
and load the sequencing chip.

\section{Data analysis}

A. Microarray data analysis for the expression analysis of long RNAs

1. Data pre-processing

Probes features are extracted using Feature Extraction Software (Agilent Technologies). We published the following description of data treatment in (Alessio et al., 2019; Chemello et al., 2019). Data have to be intra-array and inter-array normalized. For intra-array normalizations, we suggest using the Feature Extraction Software while for the inter-array the quantile normalization (normalizeQuantiles, limma R package). For filtering out bad expression values we used Found and/or Well Above Background flags calculated from the Feature Extraction Software (Agilent Technologies). If the chosen filter was not positive, we assign to the particular expression value the value of NA. This allows maintaining in the expression matrix only transcripts that have a defined expression value in a sufficient number of biological replicates. For example, in (Chemello et al., 2019) we considered only gene/probes with at least 8 available values out of a total of 10 biological replicates.

2. Statistical analyses of microarray data

Microarray data can be analyzed using the $\mathrm{R}$ statistical suite or a more user-friendly platform such as the MultiExperiment Viewer, a tool of TM4 Microarray Software Suite (Saeed et al., 2003). To identify the differentially expressed probes among myofibers, we performed one-way analysis of variance (ANOVA), but different alternatives can be explored, such as the identification of differentially expressed probes using the False Discovery Rate implemented in the Significance Analysis of Microarrays (SAM) algorithm (Tusher et al., 2001).

3. Gene ontology

Differentially expressed coding genes can be categorized according to gene ontology (GO) using different web tools (e.g., the Functional Annotation Clustering method, implemented in the DAVID database [Huang da et al., 2009] or according to pathway analyses [e.g., (Sales et al., 2013)] that implement different algorithms for the pathway analysis). Regarding IncRNAs, there are no enrichment analyses that can be performed. To infer their function, it can be performed a gene expression correlation with coding genes such as in (Guo et al., 2017; Fang et al., 2018; Cagnin et al., 2019).

\section{B. NGS expression analysis}

In all sequencing experiments, raw reads have to be trimmed for the presence of adaptors and then filtered out for their length and quality. In Chemello et al. (2019) reads longer than 18 nucleotides were used for the following analyses: The expression of miRNAs was quantized using miRDeep software (Friedlander et al., 2008). The processed reads were mapped to the known mouse miRNA precursors from miRBase database (Ver. 19) using the mapper module of miRDeep with default values. Basically, 
in this process equal reads are counted and collapsed. Reads that mapped more than 5 different locations are automatically excluded. Quantize module in miRDeep was used to normalize read counts of mature miRNAs. For a discussion about problems, software used in the analysis (normalization, read count, clustering) of single cell data see (Risso et al., 2018a; Risso et al., 2018b; Chen et al., 2019; Cole et al., 2019).

\section{$\underline{\text { Recipes }}$}

1. 1x Low TE buffer

TE buffer is a buffer solution containing Tris, a common pH buffer, and EDTA, a molecule that chelates cations like $\mathrm{Mg}^{2+}$. It is used to solubilize DNA or RNA, to protect them from degradation To make 1x Low TE buffer, see Table 18.

Table 18. Recipe for making 1x Low TE buffer

\begin{tabular}{lll}
\hline Reagent & Final conc & To make $\mathbf{5 0 0 ~} \mathbf{m l}$ \\
\hline $0.5 \mathrm{M}$ Tris- $\mathrm{HCl}, \mathrm{pH} 8.0$ & $10 \mathrm{mM}$ & $10 \mathrm{ml}$ \\
$0.5 \mathrm{M}$ EDTA & $0.1 \mathrm{mM}$ & $100 \mu \mathrm{l}$ \\
Nuclease-free water & & $489.9 \mathrm{ml}$ \\
\hline
\end{tabular}

\section{Acknowledgments}

Founding sources: CARIPARO Foundation (FIBRE-GEXP) and the University of Padova (CPDA139317) to S.C. and G.L.; the Cariplo Foundation (2016-1006) to S.C. and G.L.; the Italian Ministry of Health (GR-2011-02346845) to S.C.; the AIRC Foundation (Italy project IG2015-ID17773) to G.L.; Agenzia Nazionale di Valutazione del Sistema Universitario e della Ricerca (ANVUR) [FFABR2017 to S.C.]; Bando Grandi Attrezzature 2015 University of Padova (Italy) (Prot. 5086).

This protocol was modified from our previous works by Alessio et al., 2019 and Chemello et al., 2019. We thank all authors of the previous works.

\section{Competing interests}

The authors declare no competing interests.

\section{Ethics}

All aspects of animal care and experimentation were performed in accordance with the Guide for the Care and Use of Laboratory Animals published by the National Institutes of Health (NIH Publication No. 85-23, Revised 1996) and the Italian regulations (DL 116/92) concerning the maintenance and use of laboratory animals. Experimental procedures were approved by the he Italian Ministry of Health 
(authorization N. 305/2017-PR), and Ethical Committee of the University of Padova. All efforts were made to minimize animal suffering.

\section{References}

1. Alessio, E., Buson, L., Chemello, F., Peggion, C., Grespi, F., Martini, P., Massimino, M. L., Pacchioni, B., Millino, C., Romualdi, C., Bertoli, A., Scorrano, L., Lanfranchi, G. and Cagnin, S. (2019). Single cell analysis reveals the involvement of the long non-coding RNA Pvt1 in the modulation of muscle atrophy and mitochondrial network. Nucleic Acids Res 47(4): 1653-1670.

2. Augusto, V., Padovani, C.R., and Campos, G.E.R. (2004). Skeletal muscle fiber types in C57BL6J mice. Braz J Morphol Sci 21(2): 89-94.

3. Biga, L. M., Dawson, S., Harwell, A., Hopkins, R., Kaufmann, J., LeMaster, M., Matern, P., Morrison-Graham, K., Quick, D. and Runyeon, J. (2019). Anatomy \& Physiology, Open Oregon State, Oregon State University.gaiw

4. Cagnin, S., Chemello, F., Alessio, E. and Lanfranchi, G. (2019). Single-cell transcriptomics and proteomics of skeletal muscle. Technology and Applications, Elsevier.

5. Campbell, W. G., Gordon, S. E., Carlson, C. J., Pattison, J. S., Hamilton, M. T. and Booth, F. W. (2001). Differential global gene expression in red and white skeletal muscle. Am J Physiol Cell Physiol 280(4): C763-768.

6. Celegato, B., Capitanio, D., Pescatori, M., Romualdi, C., Pacchioni, B., Cagnin, S., Vigano, A., Colantoni, L., Begum, S., Ricci, E., Wait, R., Lanfranchi, G. and Gelfi, C. (2006). Parallel protein and transcript profiles of FSHD patient muscles correlate to the D4Z4 arrangement and reveal a common impairment of slow to fast fibre differentiation and a general deregulation of MyoDdependent genes. Proteomics 6(19): 5303-5321.

7. Chemello, F., Bean, C., Cancellara, P., Laveder, P., Reggiani, C. and Lanfranchi, G. (2011). Microgenomic analysis in skeletal muscle: expression signatures of individual fast and slow myofibers. PLoS One 6(2): e16807.

8. Chemello, F., Grespi, F., Zulian, A., Cancellara, P., Hebert-Chatelain, E., Martini, P., Bean, C., Alessio, E., Buson, L., Bazzega, M., Armani, A., Sandri, M., Ferrazza, R., Laveder, P., Guella, G., Reggiani, C., Romualdi, C., Bernardi, P., Scorrano, L., Cagnin, S. and Lanfranchi, G. (2019). Transcriptomic analysis of single isolated myofibers identifies miR-27a-3p and miR-142-3p as regulators of metabolism in skeletal muscle. Cell Rep 26(13): 3784-3797 e3788.

9. Chemello, F., Mammucari, C., Gherardi, G., Rizzuto, R., Lanfranchi, G. and Cagnin, S. (2015). Gene expression changes of single skeletal muscle fibers in response to modulation of the mitochondrial calcium uniporter (MCU). Genom Data 5: 64-67.

10. Chen, G., Ning, B. and Shi, T. (2019). Single-cell RNA-Seq technologies and related computational data analysis. Front Genet 10: 317. 
Please cite this article as: Chemello et. al., (2019). Isolation and Transcriptomic Profiling of Single Myofibers from Mice,Bio-protocol 9 (19): e3378. DOI:

11. Cole, M. B., Risso, D., Wagner, A., DeTomaso, D., Ngai, J., Purdom, E., Dudoit, S. and Yosef, N. (2019). Performance assessment and selection of normalization procedures for Single-Cell RNASeq. Cell Syst 8(4): 315-328 e318.

12. Fang, L., Wang, H. and Li, P. (2018). Systematic analysis reveals a IncRNA-mRNA co-expression network associated with platinum resistance in high-grade serous ovarian cancer. Invest New Drugs 36(2): 187-194.

13. Friedlander, M. R., Chen, W., Adamidi, C., Maaskola, J., Einspanier, R., Knespel, S. and Rajewsky, N. (2008). Discovering microRNAs from deep sequencing data using miRDeep. Nat Biotechnol 26(4): 407-415.

14. Fu, Y., Wu, P. H., Beane, T., Zamore, P. D. and Weng, Z. (2018). Elimination of PCR duplicates in RNA-seq and small RNA-seq using unique molecular identifiers. BMC Genomics 19(1): 531.

15. Guo, X., Chang, Q., Pei, H., Sun, X., Qian, X., Tian, C. and Lin, H. (2017). Long non-coding RNAmRNA correlation analysis reveals the potential role of HOTAIR in pathogenesis of sporadic thoracic aortic aneurysm. Eur J Vasc Endovasc Surg 54(3): 303-314.

16. He, P., Wei, P., Chen, X., Lin, Y. and Peng, J. (2019). Identification and characterization of microRNAs in the gonad of Trachinotus ovatus using Solexa sequencing. Comp Biochem Physiol Part D Genomics Proteomics 30: 312-320.

17. Huang da, W., Sherman, B. T. and Lempicki, R. A. (2009). Systematic and integrative analysis of large gene lists using DAVID bioinformatics resources. Nat Protoc 4(1): 44-57.

18. Krishna, S., Nair, A., Cheedipudi, S., Poduval, D., Dhawan, J., Palakodeti, D. and Ghanekar, Y. (2013). Deep sequencing reveals unique small RNA repertoire that is regulated during head regeneration in Hydra magnipapillata. Nucleic Acids Res 41(1): 599-616.

19. Mammucari, C., Gherardi, G., Zamparo, I., Raffaello, A., Boncompagni, S., Chemello, F., Cagnin, S., Braga, A., Zanin, S., Pallafacchina, G., Zentilin, L., Sandri, M., De Stefani, D., Protasi, F., Lanfranchi, G. and Rizzuto, R. (2015). The mitochondrial calcium uniporter controls skeletal muscle trophism in vivo. Cell Rep 10(8): 1269-1279.

20. Risso, D., Perraudeau, F., Gribkova, S., Dudoit, S. and Vert, J. P. (2018a). A general and flexible method for signal extraction from single-cell RNA-seq data. Nat Commun 9(1): 284.

21. Risso, D., Purvis, L., Fletcher, R. B., Das, D., Ngai, J., Dudoit, S. and Purdom, E. (2018b). clusterExperiment and RSEC: A Bioconductor package and framework for clustering of singlecell and other large gene expression datasets. PLoS Comput Biol 14(9): e1006378.

22. Saeed, A. I., Sharov, V., White, J., Li, J., Liang, W., Bhagabati, N., Braisted, J., Klapa, M., Currier, T., Thiagarajan, M., Sturn, A., Snuffin, M., Rezantsev, A., Popov, D., Ryltsov, A., Kostukovich, E., Borisovsky, I., Liu, Z., Vinsavich, A., Trush, V. and Quackenbush, J. (2003). TM4: a free, opensource system for microarray data management and analysis. Biotechniques 34(2): 374-378.

23. Sales, G., Calura, E., Martini, P. and Romualdi, C. (2013). Graphite Web: Web tool for gene set analysis exploiting pathway topology. Nucleic Acids Res 41(Web Server issue): W89-97.

24. Schiaffino, S. and Reggiani, C. (2011). Fiber types in mammalian skeletal muscles. Physiol Rev 91(4): 1447-1531. 
25. Tusher, V. G., Tibshirani, R. and Chu, G. (2001). Significance analysis of microarrays applied to the ionizing radiation response. Proc Natl Acad Sci U S A 98(9): 5116-5121.

26. Wang, Y., and Pessin, J.E. (2013). Mechanisms for fiber-type specificity of skeletal muscle atrophy. Curr Opin Clin Nutr Metab Care 16, 243-250.

27. Wellenreuther, R., Schupp, I., Poustka, A., Wiemann, S., and German C, D.N.A.C. (2004). SMART amplification combined with cDNA size fractionation in order to obtain large full-length clones. BMC Genomics 5, 36.

28. Wu, H., Gallardo, T., Olson, E.N., Williams, R.S., and Shohet, R.V. (2003). Transcriptional analysis of mouse skeletal myofiber diversity and adaptation to endurance exercise. $J$ Muscle Res Cell Motil 24, 587-592. 